Research Article

www.ijrap.net

\title{
QUANTITATIVE DETERMINATION OF QUERCETIN A BIOMARKER IN METHANOLIC EXTRACT OF LAGERSTROEMIA LANCEOLATA AND LAGERSTROEMIA PARVIFLORA LEAVES BY HPTLC METHOD
}

Shubangi W. Jadhav ${ }^{1 *}$, R. B. Jadhav ${ }^{2}$, Srinivas Rao ${ }^{3}$

${ }^{1}$ Assistant Professor, Dr. D. Y. Patil College of Pharmacy, Akurdi, Pune, Maharashtra, India

${ }^{2}$ Principal and Professor, Shivnagar Vidhya Prasarak Mandal's College of Pharmacy, Malegaon (Bk), Baramati Dist. Pune, Maharashtra, India

${ }^{3}$ Principal and Professor, Bhaskar Pharmacy College, Yenkapally, Moinabad, R.R (Dt), Hyderabad, India

Received on: 09/08/19Accepted on: 10/09/19

\author{
*Corresponding author \\ E-mail: shubhangi10jadhav@gmail.com
}

DOI: $10.7897 / 2277-4343.1005108$

\begin{abstract}
In Indian Ayurvedic system, Lagerstroemia lanceolata (L. lanceolata) and Lagerstroemia parviflora (L. parviflora) are well-known plants used for major and minor ailments. Quercetin identified from the vast plethora of plant extracts has proved to possess ethno pharmacological relevance. The present investigation is to estimate biologically active flavonoid compound, quercetin in methanolic leaves extract of $L$. lanceolata and $L$. parviflora by using high-performance thin-layer chromatography (HPTLC). After extraction and phytochemical screening, the extracts were subjected to quantification for the presence of quercetin by HPTLC. Pre coated silica gel 60 F254 is used as a stationary phase and toluene: ethyl acetate: formic acid in ratio of 7: 5: 1 is used as a mobile phase. Densitometric estimation and quantification of quercetin was carried out at $254 \mathrm{~nm}$. The standard Rf value of quercetin is 0.64 . The total peak area of the standard, quercetin was compared and the corresponding peak areas of $L$. lanceolata and $L$. parviflora extracts were estimated to be 390.6 and 5442.8 respectively. A good linear relationship 0.988 was obtained between the concentration ranges of $0.2-1.0 \mu \mathrm{g}$. This HPTLC method was found to be simple and convenient for rapid screening of active compounds and quantification of the investigated flavonoids in L. lanceolata and L. parviflora.
\end{abstract}

Keywords: Lagerstroemia lanceolata, Lagerstroemia parviflora, HPTLC, Flavonoid compounds, Quercetin.

\section{INTRODUCTION}

Nature still obliges as the man's primary source for the cure of his ailments. Research in preventive medicine showed the importance of functional nutrition in reducing the risk factor of certain chronic diseases. Innate defense system of the human body may be insufficient for the damage caused by continued oxidative stress ${ }^{1}$. Flavonoids are a group of polyphenolic compounds, which are extensively dispersed throughout the plant kingdom. Till date about 300 varieties of flavonoids are known ${ }^{2}$. Herbal medicines have situated the test of time for their efficacy, safety, cultural suitability and smaller side effects. Flavonoids are classified as flavonones, flavones, flavonols, flavanols, flavan-3ols and isoflavones according to the locations of the substitutes present on the parent molecule. Quercetin and other flavonoids have the structure to act as powerful antioxidants and have often proven so in vitro. Quercetin, being a major constituent of the flavonoid intake, could be a key in fighting several chronic degenerative diseases ${ }^{3}$. Growing scientific evidence has shown adverse side effects, like liver damage and mutagenesis, of synthetic antioxidant ${ }^{4}$. Therefore, recently there has been an upsurge of interest in natural products as antioxidants, as they inhibit the free radical reactions and protect human body from various diseases, such as cancer and diabetes. Recent studies showed that a number of plant products including poly phenolic substances (e.g., gallocatechins, delphinidin, cyanidin, gallic acid, ellagic acid, pelargonidin and sitosterol) and various plants or herbal extracts exert potent antioxidant actions, which are very well known for their healing powers ${ }^{5}$ Quercetin 5, 7, 3', 4', tetrahydroxy flavonol exhibit anti-inflammatory, antihepatotoxic ${ }^{6}$, antiulcer ${ }^{7}$, anti-allergic and antiviral actions and some of them provides protection against cardiovascular mortality ${ }^{8,9}$. Quercetin in combination with other flavonoids, inhibits a number of enzymes like bradykinin ${ }^{10}$, tyrosine kinase $^{11}$ and 5'- nucleotidase activity ${ }^{12}$. L. lanceolata Wall (Lythraceae) is a moderate to large deciduous tree, sometimes attaining 30 meters in height and 2.4 to 3.0 meters in girth with a clean cylindrical bole of 12 to 15 meters. It is found from Bombay to Kerala and in the hills of Deccan Peninsula up to an altitude of 1,200 meters. Bark is smooth, greenish or yellowish white, exfoliating in papery strips; leaves elliptic- lanceolate or broadly ovate, 6.2 to $10.0 \mathrm{~cm} \times 1.8$ to $5.0 \mathrm{~cm}$, coriaceous, glabrous, shining above, usually white or grayish blue; flowers small, white, in large panicles; capsules ellipsoid; seeds winged ${ }^{13} . L$. lanceolata has been used in the treatment of asthma, diabetes mellitus, chronic bronchitis, cold and cough. Seeds have been documented for its multiple pharmacological activities including narcotic principle. Steroid, terpenoids, phenols, flavonoids, alkaloids, ellagic acid and tannins are the major components present in the plant ${ }^{14}$. L. parviflora Roxb (Lythraceae) is a medium-sized deciduous plant indigenous to India and available even up to a height of $900 \mathrm{~m}$ in the Himalayas. The plant is used for the treatment of syphilis, sores and carbuncles ${ }^{15}$. Mazumder et al. $(2003)^{16}$ reported the antibacterial activities of the leaves of the plant and Bhakuni et al. (1969) ${ }^{17}$ reported the anti-asthmatic activity of the flowers of $L$. parviflora. The leaf juice of this plant is used in traditional medicine to treat fever in Jharkhand, India ${ }^{15}$. L. lanceolata and L. parviflora contain quercetin as an important active constituent and is predictable by HPLC method. Phytochemical assessment is one of the tools for the quality evaluation, which includes preliminary phytochemical screening, chemo profiling and marker compound analysis using current analytical techniques. In the last two decades HPTLC method has appeared as a significant tool for the qualitative and quantitative 
phytochemical analysis of herbal drugs and formulations. This includes TLC fingerprint profiles and estimation of chemical markers and biomarkers. The chief advantage of HPTLC is that several samples can be analyzed simultaneously using a small quantity of mobile phase.

\section{MATERIAL AND METHODS}

\section{Plant Material}

The leaves of L. lanceolata (Voucher no. 550/ACF/TNWLS/TAXON/14-15) and L. parviflora (Voucher no. 1240) were collected from Tansa Wildlife Sanctuary, Asangaon, Shahapur, Maharashtra and Tirupati, Andhra Pradesh respectively in March 2014. The leaves were separated and washed with sterile distilled water to remove the adhering dust particles and other unwanted materials. The leaf was air dried under room temperature. The dried plant samples were grinded to make it in powder form. The powdered samples were stored in clean, dry and sterile container for further use.

\section{Reagents and Materials}

All chemicals and solvents used were of analytical grade and obtained from SD Fine-Chem. Ltd. (Mumbai, India). The standard Quercetin was purchased from Lobo Chem, Mumbai, India (purity $>97 \%$ ). Stock solutions $(1 \mathrm{mg} / \mathrm{ml})$ of the standards were prepared daily in methanol immediately before use. TLC aluminum plates pre-coated with silica gel 60 F254 (100 x 100 $\mathrm{mm}, 0.2 \mathrm{~mm}$ thick) used were obtained from E. Merck Ltd (Mumbai, India).

\section{Extraction of Plant Material for HPTLC Analysis}

The shade dried plant material was coarsely powdered and subjected to extraction with petroleum ether using maceration method. The extraction was continued till the defatting of the material had taken place. $200 \mathrm{gm}$ of dried plant material (leaves of $L$. lanceolata and L. parviflora) was exhaustively extracted with methanol as solvent using maceration method. The extract was evaporated above their boiling points and stored in an airtight container, free from any contamination until it was used.

\section{Preparation of Standard and Sample Solutions}

Quercetin standard stock solutions were prepared by dissolving $10 \mathrm{mg}$ of it in $10 \mathrm{ml}$ of methanol. From this $2 \mu \mathrm{l}$ solution was applied using sample applicator. $100 \mathrm{mg}$ of methanolic extract of $L$. lanceolata and $L$. parviflora was dissolved in $10 \mathrm{ml}$ of methanol and filtered. The filtrate $(10 \mathrm{mg} / \mathrm{ml})$ was used for the HPTLC chemo profiling.

\section{TLC Study}

Thin layer chromatography was conducted to study the number of compounds present in the extract. The adsorbent used for thin layer chromatography was silica gel $60 \mathrm{~F} 254$. The pre-coated TLC plate (Merck, Germany) was heated in an oven for activation. $1 \mathrm{ml}$ of the standard flavonoid quercetin and the methanol extract were applied, dried and then set aside in the developing chamber. The chamber was drenched with the solvents for $20 \mathrm{~min}$ at room temperature. Numerous solvent systems were tried to recognize an appropriate developing solvent system for the separation of compounds. After the progress of the plate, it was air-dried, then the numbers of spots were noted and $\mathrm{Rf}$ values were calculated.

\section{HPTLC Analysis}

Instrument: CAMAG Automatic TLC Sampler, with win CATS software.

Stationary phase: TLC plates silica gel $60 \mathrm{~F} 254$ pre coated layer $(20 \mathrm{~cm} \mathrm{X} 10 \mathrm{~cm})$, thickness $0.2 \mathrm{~mm}$.

No. of tracks: 8 , band length: $8 \mathrm{~mm}$.

Mobile phase: Toluene: Ethyl acetate: Formic acid (7:5:1)

Standard: Light yellow powder

Sample: Brown powder

Solubility: Methanol

Standard concentration: $50 \mu \mathrm{g} / \mathrm{ml}$

Standard Injection volumes ( $\mu \mathrm{l}): 2,4,6,8,10 \mu \mathrm{l}$

Sample concentration: $1 \mathrm{mg} / \mathrm{ml}$

Sample application volumes $(\mu \mathrm{l}): 2 \mu \mathrm{l}$

Development chamber: Twin trough chamber (20 X 10)

Development mode: Ascending mode

Distance run: $75 \mathrm{~mm}$

Scanning wavelength: $254 \mathrm{~nm}$

\section{Preparation of the Plates}

The plates used for HPTLC was silica gel $60 \mathrm{~F} 254$ (E.MERCK $\mathrm{KGaA}) .100 \mu \mathrm{g} / \mathrm{ml}$ of the standard was applied in the form of bands using LINOMAT IV applicator. The volumes applied were $2,4,6,8$ and $10 \mu \mathrm{l}$ and the sample concentration was $10 \mathrm{mg} / \mathrm{ml}$. The mobile phase used was toluene: ethyl acetate: formic acid (7:5:1). The chromatograph was developed, dried at room temperature and scanned at $254 \mathrm{~nm}$. The average peak area of the standard was calculated. Regression equation was obtained, via the Win Cats software using the calibration curve of the standard drug concentration (X-axis) over the average peak height / area (Y-axis).

\section{Estimation of Quercetin in Herbal Extracts}

Estimation of quercetin in extracts of $L$. lanceolata and $L$. parviflora. Using the regression equation obtained from the standard curve, the content of quercetin was quantified, and the mean peak height/area of the sample was calculated.

\section{RESULTS AND DISCUSSION}

Preliminary phytochemical analysis of methanol extracts of the leaves of $L$. lanceolata and $L$. parviflora revealed the occurrence of amino acids, phenols, sterols, alkaloids, terpenoids, carbohydrates, flavonoids and tannins. The TLC procedure was optimized with a sight to separate the compounds and to recognize one of the phytochemical flavonoids (quercetin) in the extract. At first toluene: ethyl acetate: formic acid in unreliable ratios was tried along with numerous combinations of other solvents. The final system consists of toluene: ethyl acetate: formic acid $(7: 5: 1 \mathrm{v} / \mathrm{v} / \mathrm{v})$ which gave a sharp and well-defined band with $\mathrm{Rf}=0.64$ for quercetin. The identity of the quercetin 
bands in sample chromatograms was established by the chromatogram obtained from the sample and reference standard solution $^{18}$. HPTLC analysis of the methanol leaf extract of $L$. lanceolata and $L$. parviflora was carried out along with the standard quercetin and toluene: ethyl acetate: formic acid (7:5:1) as the mobile phase. The number of bands obtained were three to four (Figure 1-3). The use of standard makes sure the concentration and ratio of the quercetin compound in the leaf (Figure 4-6). This result matches with the study of Sachin et al., ${ }^{19}$ who finds a good correlation of quercetin in the dried flowers of Nymphaea stellata. HPTLC studies revealed well resolved peaks of extracts containing quercetin. The spots of the entire chromatogram were visualized under UV $254 \mathrm{~nm}$ and the percentage of quercetin ( $\mathrm{Rf} 0.64$ ) in $L$. lanceolata and $L$. parviflora extracts was found to be 0.05751 and $0.8377 \%$ Table 1. HPTLC fingerprinting is established to be an accurate, liner, precise method for herbal identification and can be used further in authentication and characterization of the medicinally important plant $^{20}$.

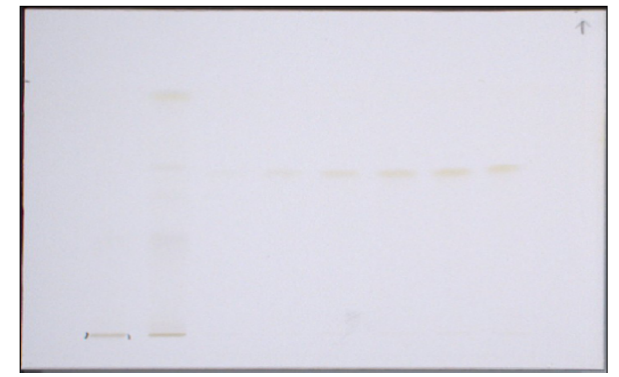

Figure 1: Thin layer chromatography in normal light

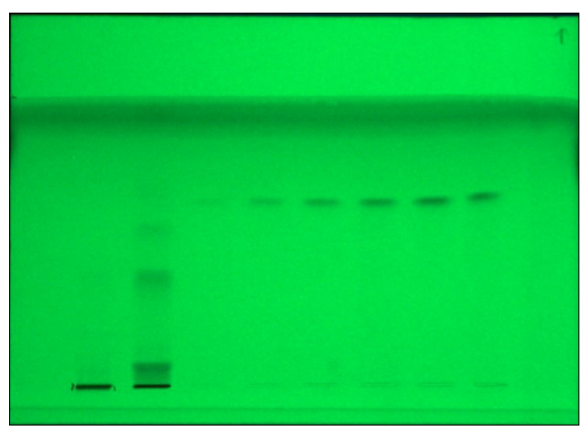

Figure 2: Thin layer chromatography in short U.V

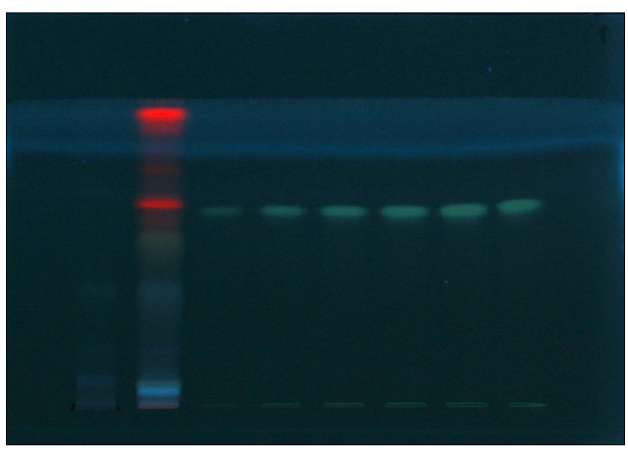

Figure 3: Thin layer chromatography in long U.V

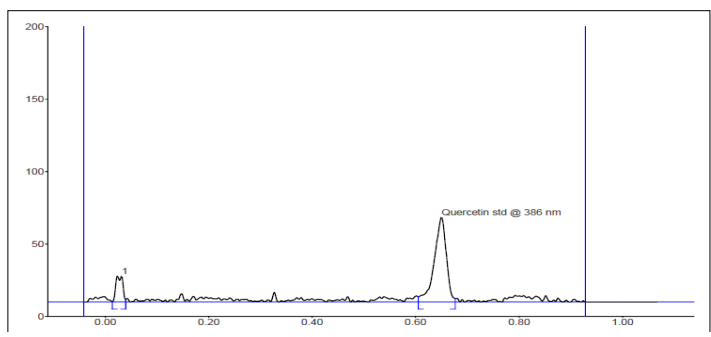

Figure 4: Chromatogram of standard quercetin

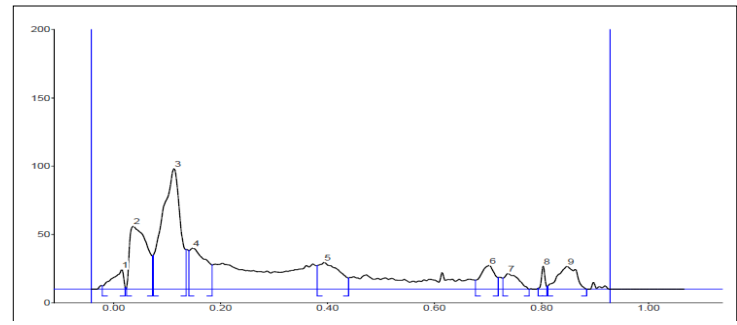

Figure 5: Chromatogram of L. lanceolata extract

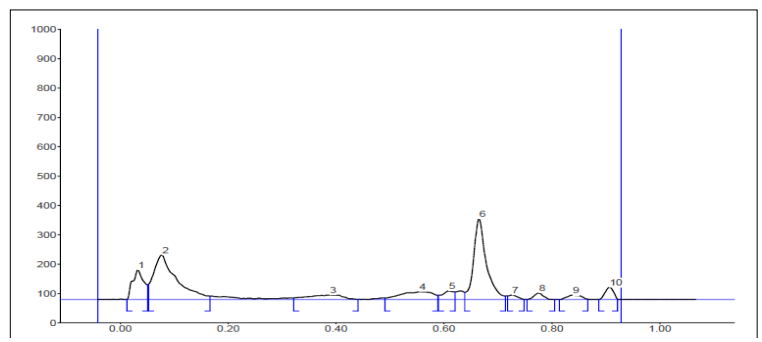

Figure 6: Chromatogram of L. parviflora extract

Table 1: Results of HPTLC estimation

\begin{tabular}{|c|c|c|}
\hline Estimation & Area & L. lanceolata $(\%)$ \\
\hline \multirow{3}{*}{ Quercetin } & 390.6 & 0.0039 \\
\cline { 2 - 3 } & & L. parviflora \\
\cline { 2 - 3 } & 5442.8 & 0.054482 \\
\hline
\end{tabular}

\section{CONCLUSION}

The phytochemical studies showed the occurrence of the majority of the biologically active constituents in the plant. It is usually realized that for monitoring superiority, HPTLC fingerprinting is perfect which involves assessment between a standard and a sample. The chromatographic studies conducted with the methanol leaf extract of L. lanceolata and L. parviflora revealed an appreciable amount of flavonoid quercetin, which confirms its medicinal value.

\section{ACKNOWLEDGMENT}

Authors are thankful to Tansa Wildlife Sanctuary, Savitribai Phule Pune University, Jawaharlal Nehru Technological University, Hyderabad (JNTUH) and Dr. D. Y. Patil College of Pharmacy, Akurdi for providing the necessary assistance.

\section{REFERENCES}

1. Halliwell B. Free radicals, antioxidants, and human disease: curiosity, cause, or consequence. Lancet 1994; 344: 721724.

2. Anonymous, Indian Pharmacopoeia, Vol II. Controller of Publications, New Delhi; 1996. p. 53. 
3. Bouktaib M, Lebrun S, Atmani A, Rolando C. Hemi synthesis of all the O-monomethylated analogues of quercetin including the major metabolites, through selective protection of phenolic functions. Tetrahedron 2002; 58: 10001-10009.

4. Singh R, Singh M, Chandra L, Bhat D, Arora M, et al. In vitro antioxidant and free radical scavenging activity of Macrotyloma uniflorum (Gahatdal) from Kumauni region. Int J Fundam Appl Sci 2012; 1: 9-11.

5. Kiran B, Lalitha V, Raveesha K. Psoralea corylifolia L. a potent medicinal plant with broad spectrum of medicinal properties. Int J Fundam Appl Sci 2013; 2: 20-22.

6. Cesarone MR, Laurora G, Ricci A, Belcaco G, Pomante P. Acute effects of hydroxyethylrutosides on capillary filtration in normal volunteers, patients with various hypo tensions and in patients with diabetic micro angiopathy. $\mathrm{J}$ Vas Disease 1992; 21: 76-80

7. Clack W, Heller W, Michel C, Saran M. Effect of flavonoid substances on histamine toxicity, anaphylactic shock and histamine-enhanced capacity to dye. J Allergy 1950; 21: 133-147.

8. Colergie Smith PO, Thomas P, Scurry JH, Dormandy JA. Causes of various ulceration, a New Hypothesis. Br Med J 1980; 296: 1726-7.

9. Hertog MGL, Hollman PCH, Katan Klohout D. Intake of potentially anti carcinogenic flavonoids and their determinants in adults in the Netherlands. Nutr Cancer 1993; 20: 21-29.

10. Bamard DL, Smee DF, Huffman JH, Meyerson CR, Sidwell RW. Review of Quercetin and related bio flavonoids. Chemotherapy 1993; 39: 203-11.

11. Hur CQ, Chen K, Shi Q, Kikushkie RE, Cheng YC, Lee $\mathrm{KH}$. Apoptosis of HIV infected cell following treatment with Shosoikorso. J Nat Pro 1994; 57: 42-50.
12. Beladi I, Musci R, Pusztai M, Bakay I, Rosztoczy M. Bioactivity of flavonoids. Stud Org Chem 1987; 57: 42-50.

13. Marg KK. National institute of science communication and information resources. DIO 2016; 25: 01-1993.

14. Bhusnure OG, Alagawadi KR, Giram PS, Poul BN. Study of analgesic and anti- inflammatory activities of Lagerstroemia lanceolata Wall seed extract. Int J Pharm and Clin Res 2009; 1(3): 127-130.

15. Jain SK, Tarafdar CR. Medicinal plant-Lore of the santals. Econ Bot 1970; 24: 241-243.

16. Mazumder A, Saha BP, Basu SP, Mazumder R. Antibacterial activity of methanolic extract of leaves of Lagerstroemia parviflora. Indian J Nat Prod 2003; 19: 20 24.

17. Bhakuni DS, Dhar ML, Dhar MM, Dhawan BN, Mehrotra BN. Screening of Indian plants for biological activity. Part II. Indian J Exp Biol 1969; 7: 250-256.

18. Sachin UR, Patil PR, Salunkhe VR, Dhabale PN, Burade KB. HPTLC method for quantitative determination of quercetin in hydroalcoholic extract of dried flower of Nymphaea stellata willd. Int J Chem Tech Res 2009; 1 (4): 931-936.

19. Kalaiselvi M, Kumar GR, Sophia D, Gopalakrishnan VK, Uma CS. Secondary metabolite credentials of Evolvulus alsinoides by high performance thin layer chromatography (HPTLC). J Biomed Res 2012; 26: 1-8.

\section{Cite this article as:}

Shubangi W. Jadhav et al. Quantitative determination of Quercetin a Biomarker in methanolic extract of Lagerstroemia lanceolata and Lagerstroemia parviflora leaves by HPTLC method. Int. J. Res. Ayurveda Pharm. 2019;10(5):72-75 http://dx.doi.org/10.7897/2277-4343.1005108 every effort has been taken to verify the accuracy of the content published in our Journal. IJRAP cannot accept any responsibility or liability for the site content and articles published. The views expressed in articles by our contributing authors are not necessarily those of IJRAP editor or editorial board members. 